\title{
State of Canadian Pacific Salmon in 2019 and 2020: Responses to Changing Climate and Habitat
}

\author{
Sue C.H. Grant ${ }^{1}$, Bronwyn L. MacDonald ${ }^{1}$, Dawn Lewis ${ }^{2}$, Niki Wilson ${ }^{3}$, Jennifer L. Boldt ${ }^{2}$, David A. \\ Patterson $^{4}$, Kendra A. Robinson ${ }^{4}$, Ian Perry ${ }^{5}$, Jackie King ${ }^{2}$, Chrys M. Neville ${ }^{2}$, and Dan T. Selbie ${ }^{6}$ \\ ${ }^{1}$ Fisheries and Oceans Canada, Regional Headquarters 200-401 Burrard Street, Vancouver, BC, Canada \\ ${ }^{2}$ Fisheries and Oceans Canada, Pacific Biological Station 3190 Hammond Bay Road, Nanaimo, BC, Canada \\ ${ }^{3}$ Science Communication Contractor with Fisheries and Oceans Canada \\ ${ }^{4}$ Fisheries and Oceans Canada, CRMI Resource and Environmental Management, Simon Fraser University, 8886 \\ University Drive, Burnaby, BC, Canada \\ ${ }^{5}$ Fisheries and Oceans Canada, Institute of Ocean Sciences 9860 West Saanich Road, Sidney, BC, Canada \\ ${ }^{6}$ Fisheries and Oceans Canada, Cultus Lake Laboratory 4222 Columbia Valley Road, Cultus Lake, BC, Canada
}

Keywords: salmon, productivity, climate change, habitat change, abundance, trends, Pacific, status, marine, freshwater, ecosystems

Global climate change is the overarching driver of Canadian Pacific salmon trends (Grant et al. 2019). Average land-ocean temperature has risen by $1^{\circ} \mathrm{C}$ over the last century (IPCC 2018), and the last six years were the warmest on record (Fig. 1; NOAA 2020). This trend is accelerating, emphasizing the need to dramatically reduce greenhouse gas emissions globally (IPCC 2014; White et al. 2016; Holsman et al. 2018; Bush and Lemmen 2019).

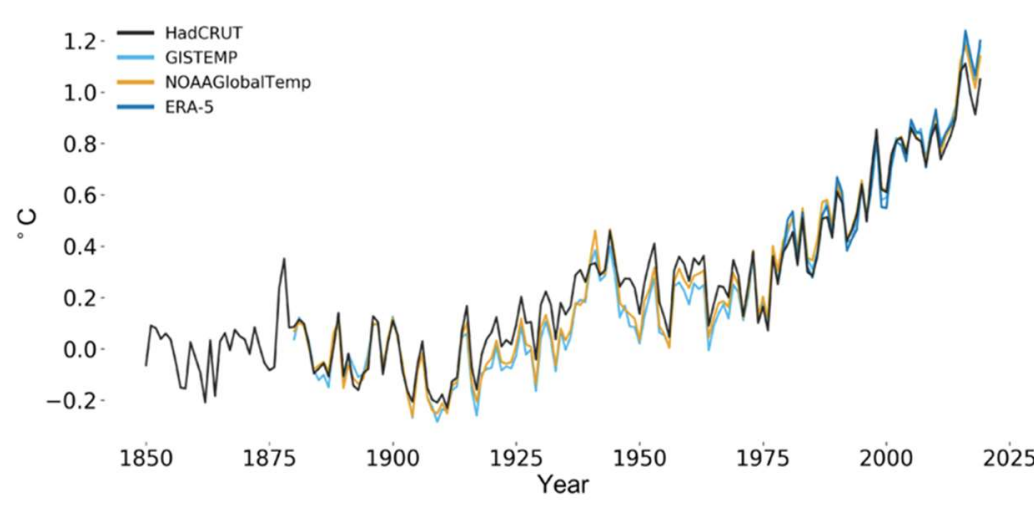

Fig. 1. Global annual mean temperature difference from preindustrial conditions (1850-1900). Canada's temperature increases are double this global rate of warming, typical of countries occupying northern latitudes. Source: Met Office Hadley Centre and the Climatic Research Unit at the University of East Anglia, UK (HadCRU) presented in World Meteorological Organization, 2020. WMO Statement on the State of Global Climate Change in 2019 (WMO-No. 1248), Fig. 1, Page 6).

Pacific salmon productivity and growth are impacted by global climate warming through changes in their freshwater and marine environments (Holsman et al. 2018; IPBES 2018; Bush and Lemmen 2019; Grant et al. 2019; Boldt et al. 2020). Other factors that contribute to salmon trends like habitat changes, disease, contaminants, hatcheries and fisheries are embedded within this global climate change context.

Rising air temperatures are warming freshwater ecosystems where salmon spend the first part of their lives incubating as eggs in their spawning gravel, and rearing as juveniles for up to two years. In British Columbia (BC), spring and summer months were notably warmer than average from 2016 to 2019, with the exception of summer 2019, which was more variable (PCIC 2019). Air temperature anomalies have been even greater in the Yukon than $\mathrm{BC}$, due to its more northern location (Fig. 2; Bush and Lemmen 2019).

Increasing temperatures are compounded by heat waves, which are expected to become more frequent and longer lasting (IPCC 2014). In BC in June 2021, an unprecedented heat wave set all time high air temperature records in multiple locations across the province, and broke the highest temperature ever recorded in Canada by greater than $1^{\circ} \mathrm{C}$ on two consecutive days (Environment \& Climate Change Canada 2021).

Warming temperatures in spring months contribute to earlier onset of snowmelt. In 2016, 2018, and 2019, early snowmelt in most regions of BC resulted in below-average snowpacks by the second week of May, which in 2016 set record lows relative to the $\sim 30$-year time series. In 2017, the onset of snowmelt began several weeks later than normal, though extreme hot temperatures led to rapid snow melt in the second half of May. By June 2017, 
snowpacks were anomalously low in northern latitudes. Early loss of snowpack reduces the cool water inputs into rivers and lakes from snowmelt in warmer summer months.

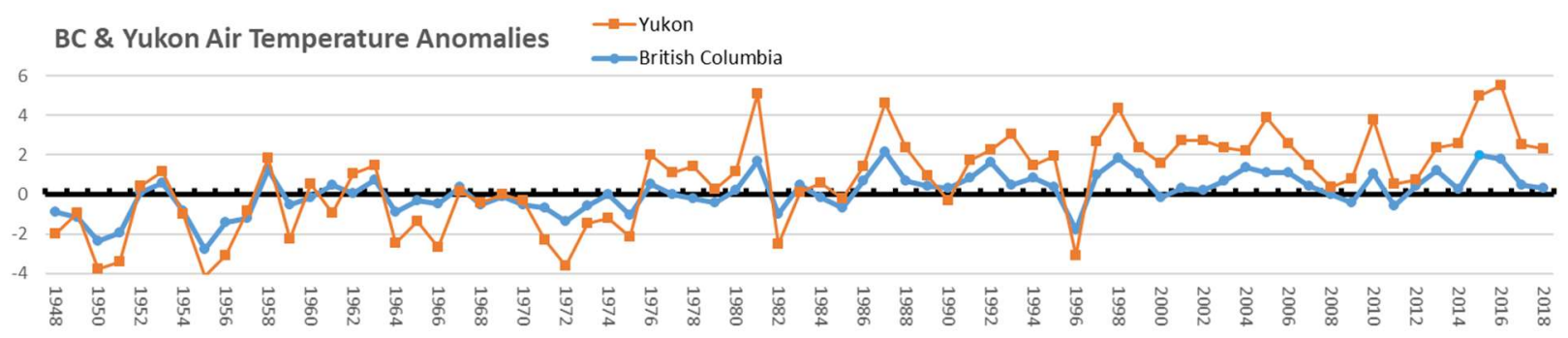

Fig. 2. Canadian gridded temperature and precipitation anomalies (CANGRD) from the Government of Canada: https://climatechange.canada.ca/climate-data/\#/historical-gridded-data. Temperatures from 2016 to 2018 coincide with the freshwater residence period of 2021 salmon returns with the exception of pinks that also used freshwater habitats in 2019. These data are interpolated from adjusted and homogenized climate station data at a $50 \mathrm{~km}$ resolution. Anomalies represent the departure from a mean reference period (1961-1990). Temperature anomalies are expressed as degree Celsius $\left({ }^{\circ} \mathrm{C}\right)$.

Correspondingly, river temperatures in a number of systems have been warmer. For example, summer river temperatures have increasingly exceeded the optimal temperature ranges of some salmon populations, particularly adult sockeye that migrated to their upstream spawning grounds in the Fraser watershed from 2016-2018 (DFO 2021). River temperatures above $18^{\circ} \mathrm{C}$ can result in decreased adult salmon swimming performance, and above $20^{\circ} \mathrm{C}$ can increase adult mortality, adult disease, egg viability, and legacy effects that have negative impacts on juvenile condition (Tierney et al. 2009; Burt et al. 2011; Eliason et al. 2011; Sopinka et al. 2016).

High in-river spawning and incubation temperatures can have population-specific negative effects on fertilization success and embryo survival, affect timing of hatch (Whitney et al. 2014), emergence (Macdonald et al. 1998), and reduce swimming endurance and impair swimming behavior of fry (Burt et al. 2012). For juveniles that rear in freshwater, warmer temperatures can improve juvenile growth rates when prey are not limiting (Brett 1971, Edmundson and Mazumder 2001), and also increase the length of the growing season in some areas (Schindler et al. 2005). The specific freshwater conditions each salmon population is exposed to will vary by system; however, as temperatures continue to increase, the net effect on salmon populations is expected to be negative (Crozier et al. 2019, 2021).

In addition to rising temperatures, global climate change affects patterns in precipitation. Record summer droughts have affected BC in recent years, including 2015, 2017, and 2018. The most significant of these occurred in 2017, during which records were set for the driest season, with almost no rain falling in southern BC from June to late October. In 2018, BC experienced extensive dry conditions from July to November due to a lack of precipitation during this period, and an early spring heatwave that depleted snowpacks early. In 2019, a spring heatwave created dry conditions across the province, and drove down streamflows. Heavy rains in July relieved the drought, and by October most of the province had returned to normal. Increasing frequency of drought in recent years has lowered river flows, potentially blocking access to spawning habitat, stranding salmon, and increasing their exposure to predators.

Profound changes are also occurring in the marine ecosystems, where Canadian Pacific Salmon spend the latter parts of their lives rearing as juveniles for one or more years before they return to freshwater to spawn. Water temperatures have been warmer than average in the Northeast Pacific Ocean in recent decades, and were unusually warm from 2014-2020 (Fig. 3; Boldt et al. 2020). Marine temperature records were set throughout this period (Leising and Bograd 2021). Most concerning is that oceans are not just warming in surface waters but throughout the water column. Even if air temperatures were stabilized within this century through significant reductions in greenhouse gas emissions, the ocean will continue to warm (Cheng et al. 2020).

The notable warm Blob heat wave in the Northeast Pacific Ocean was present from the latter half of 2013 to the fall of 2016 (Bond et al. 2015), occurring prior to the ocean entry of most of the salmon that will return in 2021. This marine heat wave was characterized by sea-surface-temperatures (SST) that were $3-5^{\circ} \mathrm{C}$ above seasonal averages and extended down to depths of $100 \mathrm{~m}$ (Bond et al. 2015). A strong El Niño event occurred in late 2015 to early 2016 (Ross 2017), further increasing temperatures to the hottest observed throughout the 137-year time-series (Chandler et al. 2017). 


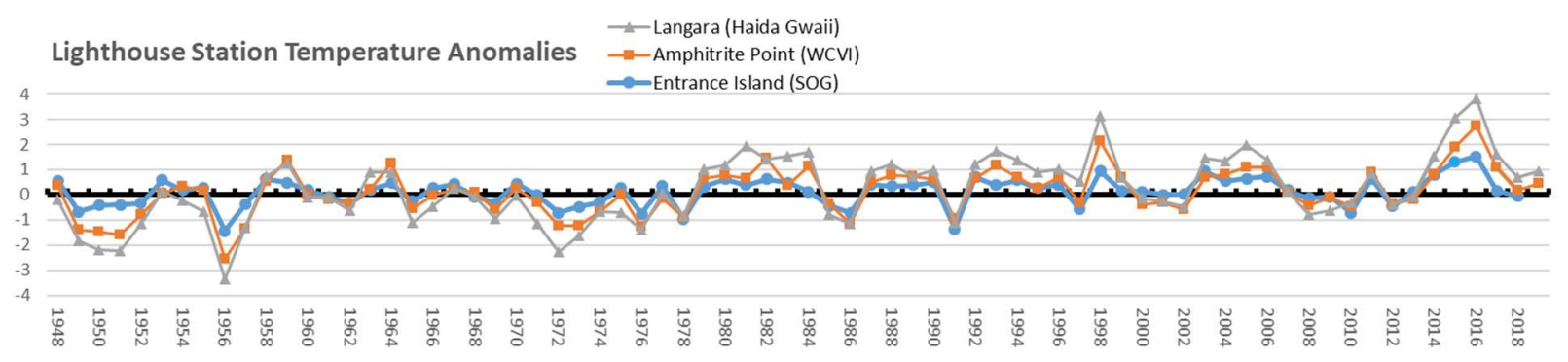

Fig. 3. Annual average sea-surface-temperature anomalies from Fisheries \& Oceans Canada lighthouse stations: https://www.dfo-mpo.gc.ca/science/data-donnees/lightstations-phares/index-eng.html. The 2018 and 2019 temperatures at the end of the time series coincide with the marine residence period of some sockeye, chum and Chinook salmon returning in 2021. Note there are gaps in the 2019 data points for these sites. Anomalies represent the departure from a mean reference period (1961-1990). Temperature anomalies are expressed as degree Celsius $\left({ }^{\circ} \mathrm{C}\right)$.

There was a return to near-average temperatures in 2017 and 2018, likely due to the cooling effect of the La Niña that persisted until the second half of 2018 (Ross and Robert 2018, 2019). In 2017, warmer than normal temperatures persisted below $100 \mathrm{~m}$, then returned near normal in 2018. New heatwaves were observed in the late summer and fall of 2018 through 2020 (Hannah et al. 2019; Ross and Robert 2020; Leising and Bograd 2021). The 2019 MHW was the third largest and longest on record, and warmer than normal subsurface temperatures were observed once more at about 100m. The 2020 marine heatwave formed in May 2020 and peaked in size in September 2020 as the second largest MHW recorded since 1982 (Leising and Bograd 2021). This MHW fell below the size requirements of MHW classification in early April 2021; however, in late April another large MHW began to form and is continuing to expand as of July 2021 (Leising and Bograd 2021).

Warm ocean temperatures may be harmful to salmon through their effect on zooplankton community composition, near the base of the salmon food web (Mackas et al. 2007). In warm Blob years in the Northeast Pacific Ocean, zooplankton communities shifted towards a greater abundance of smaller lipid-poor southern copepod species. These species are considered less nutritious for animals feeding on them. Concurrently during this period, there was a decrease in larger, more nutritious, lipid-rich zooplankton species (Mackas et al. 2007; Young et al. 2018; Galbraith and Young 2020).

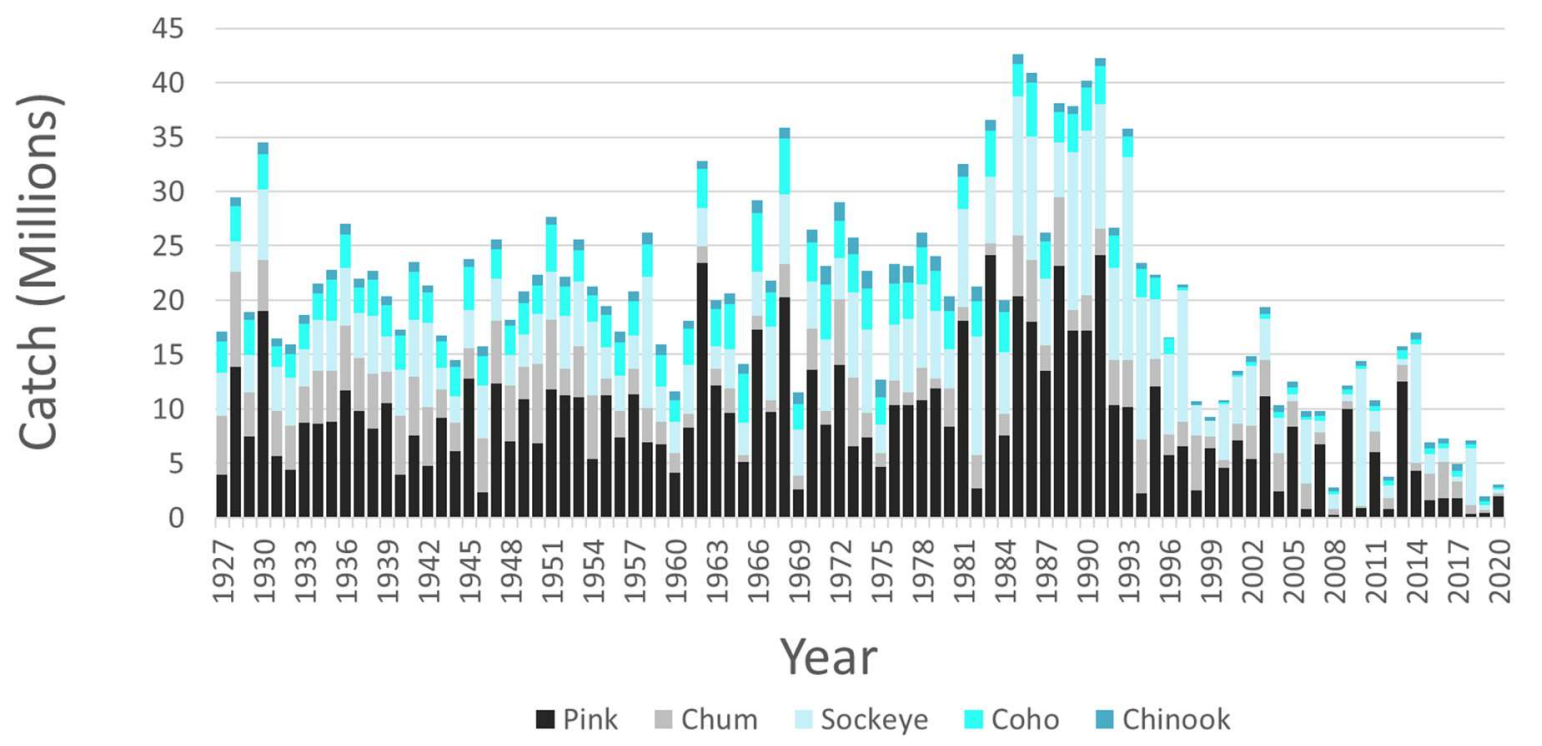

Fig. 4. Commercial, recreational and Indigenous subsistence catch of Canadian pink, chum, sockeye, coho and Chinook Salmon (Grant et al. 2019; NPAFC statitics: https://npafc.org/statistics/). Average catch from 19251993 was 24.2 million, and from 1994-2017 was 11.6 million. Returns in the last two years were extremely low at 1.9 million in 2019 and 3.1 million in 2020.

Salmon productivity and abundances are generally declining in response to these large changes in their ecosystems. Catch for all five Fisheries \& Oceans Canada managed Pacific Salmon species has declined in the past 
decade (Fig. 4; Grant et al. 2019; NPAFC statistics: https://npafc.org/statistics/). This is due to both declines in target salmon population abundances, and constraints placed on mixed-stock fisheries to protect co-migrating salmon populations in poor status. Catch has dropped from an average of 24 million between 1927 and 1993, down to 12 million in recent decades. The last six years, catch averaged 4 million, and was particularly low in 2019 and 2020 at 1.9 million and 3.1 million, respectively (Fig. 4).

Despite large reductions in catch, numbers of fish reaching the spawning grounds have continued to generally decline for many Canadian Pacific Salmon populations. Though there are exceptions among all species, where particular populations are not exhibiting declining trends.

Total escapements of Chinook in 2019 and 2020 were poor, which continued the recent trend of generally low abundances (Grant et al. 2019). There are some exceptions to these trends, particularly for populations on the east coast of Vancouver Island. Chinook have generally been declining throughout their range from Oregon up to Alaska (Sharma et al. 2013; Kilduff et al. 2014; Dorner et al. 2018). They are not just declining in abundances, but are also returning at younger ages and smaller sizes, and are producing fewer eggs-per-female (Ohlberger 2013; Ohlberger et al. 2018; Xu et al. 2020). A number of these populations are facing an imminent threat of extinction (COSEWIC 2020).

Sockeye returns in 2019 and 2020 were also poor, continuing the low abundance trends observed for this species in recent years, particularly in central to southern latitudes of BC (Grant et al. 2019; Hyatt et al. 2021). Fraser River sockeye returns reached record low numbers in 2019 of 486,000, and hit a new record low again in 2020 of 292,000; compared to a long term average of 7.2 million returns (1950-2020). A number of these populations are facing an imminent threat of extinction (COSEWIC 2017). Populations in the Taku River of the Northern BC-Alaska transboundary region were exceptions to the sockeye trend in 2020.

Coho marine survival remained low relative to the 1980s. Returns in 2019 and 2020 were generally below average, though there were some populations that had returns that were closer to average. Several new survival/escapement coho indicators are in development, including for Cowichan and Sakinaw.

Pink salmon returns in 2020 were mixed but generally better than other species. Chum salmon generally exhibited poor returns in 2019 and 2020, in contrast with their recent positive trend for most populations (Grant et al. 2019).

\section{REFERENCES}

Boldt, J.L., A. Javorski, and P.C. Chandler (Editors). 2020. State of physical, biological and selected fishery resources of Pacific Canadian marine ecoystems in 2019. Can. Tech. Rep. Fish. Aquat. Sci. 3377. 288 pp. (Available at https://www.dfo-mpo.gc.ca/oceans/publications/soto-rceo/2019/index-eng.html)

Bond, N.A., M.F. Cronin, H. Freeland, and N. Mantua. 2015. Causes and impacts of the 2014 warm anomaly in the NE Pacific. Geophys. Res. Lett. 42(9): 3414-3420. doi:10.1002/2015GL063306.

Brett, J.R. 1971. Energetic responses of salmon to temperature. A study of some thermal relations in the physiology and freshwater ecology of sockeye salmon (Oncorhynchus nerka). Am. Zool. 11(1): 99-113. doi:198.103.39.129.

Burt, J.M., S.G. Hinch, and D.A. Patterson. 2011. The importance of parentage in assessing temperature effects on fish early life history: a review of the experimental literature. Rev. Fish Biol. Fish. 21: 377-406. doi:10.1007/s11160-010-9179-1.

Burt, J.M., S.G. Hinch, and D.A. Patterson. 2012. Developmental temperature stress and parental identity shape offspring burst swimming performance in sockeye salmon (Oncorhynchus nerka). Ecol. Freshw. Fish 21(2): 176-188. doi:10.1111/j.1600-0633.2011.00535.x.

Bush, E., and D.S. Lemmen (Editors). 2019. Canada's changing climate report. Government of Canada, Ottawa. 734 pp. (Available at www.ChangingClimate.ca/CCCR2019)

Chandler, P.C., S.A. King, and J. Boldt (Editors). 2017. State of the physical, biological and selected fishery resources of Pacific Canadian marine ecosystems in 2016. Can. Tech. Rep. Fish. Aquat. Sci. No. 3225.

Cheng, L., J. Abraham, J. Zhu, K.E. Trenberth, J. Fasullo, T. Boyer, R. Locarnini, B. Zhang, F. Yu, L. Wan, X. Chen, X. Song, Y. Liu, and M.E. Mann. 2020. Record-setting ocean warmth continued in 2019. Adv. Atmos. Sci. 37(2): 137-142. doi:10.1007/s00376-020-9283-7.

COSEWIC. 2017. COSEWIC assessment and status report on the sockeye salmon Oncorhynchus nerka, 24 Designatable Units in the Fraser River Drainage Basin, in Canada. Committee on the Status of Endangered Wildlife in Canada, Ottawa. ON. 179 pp. (Available from https://www.sararegistry.gc.ca/virtual_sara/files/cosewic/srSockeyeSalmon2017e.pdf)

COSEWIC. 2020. COSEWIC assessment and status report on the Chinook Salmon Oncorhynchus tshawytscha, 
Designatable Units in Southern British Columbia (Part One-Designatable Units with no or low levels of artificial releases in the last 12 years), in Canada. 283 pp. (Available from https://wildlifespecies.canada.ca/species-risk-registry/virtual_sara/files/cosewic/ChinookSalmon-v00-2019-Eng.pdf)

Crozier, L.G., B.J. Burke, B.E. Chasco, D.L. Widener, and R.W. Zabel. 2021. Climate change threatens Chinook salmon throughout their life cycle. Commun. Biol. Springer US. doi:10.1038/s42003-021-01734-w.

Crozier, L.G., M.M McClure, T. Beechie, S.J. Bograd, D.A. Boughton, M. Carr, T.D. Cooney, J.B. Dunham, C.M. Greene, M.A. Haltuch, E.L. Hazen, D.M. Holzer, D.D. Huff, R.C. Johnson, C.E. Jordan, I.C. Kaplan, S.T. Lindley, N.J. Mantua, P.B. Moyle, J.M. Myers, M.W. Nelson, B.C. Spence, L.A. Weitkamp, T.H. Williams, and E. Willis-Norton. 2019. Climate vulnerability assessment for Pacific salmon and steelhead in the California Current Large Marine Ecosystem. PLoS One 14(7): e0217711. doi:10.1371/journal.pone.0217711.

DFO. 2021. Fraser River environmental watch. (Available at https://www.pac.dfo-mpo.gc.ca/science/habitat/frwrfo/index-eng.html)

Dorner, B., M.J. Catalano, and R.M. Peterman. 2018. Spatial and temporal patterns of covariation in productivity of Chinook salmon populations of the northeastern Pacific Ocean. Can. J. Fish. Aquat. Sci. 75(7): 1082-1095. doi:10.1139/cjfas-2017-0197.

Edmundson, J.A., and A. Mazumder. 2001. Linking growth of juvenile sockeye salmon to habitat temperature in Alaskan lakes. Trans. Am. Fish. Soc. 130: 644-662. doi:10.1577/15488659(2001)130<0644:LGOJSS $>2.0$. CO;2.

Eliason, E.J., T.D. Clark, M.J. Hague, L.M. Hanson, Z.S. Gallagher, K.M. Jeffries, M.K. Gale, D.A. Patterson, S.G. Hinch, and A.P. Farrell. 2011. Differences in thermal tolerance among sockeye salmon populations. ScienceVol. 332(6025): 109-112. doi:10.1126/science.1199158.

Environment \& Climate Change Canada. 2021. Environment and Climate Change Canada warns western Canadians about dangerous record-high temperatures. (Available at https://www.canada.ca/en/environmentclimate-change/news/2021/06/environment-and-climate-change-canada-warns-western-canadians-aboutdangerous-record-high-temperatures.html)

Galbraith, M., and K. Young. 2020. West coast British Columbia zooplankton biomass anomalies 2019. In State of the physical , biological and selected fishery resources of Pacific Canadian marine ecosystems in 2019. Can. Tech. Rep. Fish. Aquat. Sci. No. 3377. Edited by J.L. Boldt, A. Javorski, and P.C. Chandler. pp. 63-68. (Available at https://dfo-mpo.gc.ca/oceans/publications/soto-rceo/2018/index-eng.html)

Grant, S.C.H., B.L. MacDonald, and M.L. Winston. 2019. State of the Canadian Pacific Salmon: Responses to Changing Climate and Habitats. Can. Tech. Rep. Fish. Aquat. Sci. 3332: ix +50 pp. (Available at http://www.dfo-mpo.gc.ca/species-especes/publications/salmon-saumon/state-etat-2019/abstractresume/index-eng.html)

Hannah, C., S. Page, and T. Ross. 2019. Ocean surface temperatures in 2018: another marine heat wave? In State of the physical, biological and selected fishery resources of Pacific Canadian marine ecosystems in 2018. Can. Tech. Rep. Fish. Aquat. Sci. No. 3314. Edited by J.L. Boldt, J. Leonard, and P.C. Chandler. pp. 31-36. (Available at https://dfo-mpo.gc.ca/oceans/publications/soto-rceo/2018/index-eng.html)

Holsman, K., A. Hollowed, I. Shin-Ichi, S. Bograd, E. Hazen, J. King, F. Mueter, and R.I. Perry. 2018. Climate change impacts, vulnerabilities and adaptations: North Pacific and Pacific Arctic marine fisheries. In Impacts of climate change on fisheries and aquaculture: synthesis of current knowledge, adaptation and mitigation options. Edited by M. Barange, T. Bahri, M.C.M. Beveridge, K.L. Cochrane, S. Funge-Smith, and F. Poulain. FAO Fisheries and Aquaculture Technical Paper, No. 627. FAO, Rome. pp. 113-138. (Available at http://www.fao.org/3/i9705en/i9705en.pdf)

Hyatt, K.D., H.W. Stiff, and M.M. Stockwell. 2021. Coast-wide sockeye salmon performance indicators, regional overview of trends, 2020 returns, and 2021-2023 outlook. In State of the physical, biological and selected fishery resources of Pacific Canadian marine ecosystems in 2020. Edited by J.L. Boldt, A. Javorski, and P.C. Chandler. Can. Tech. Rep. Fish. Aquat. Sci. 3434. pp. 112-116.

IPBES. 2018. The regional assessment report on biodiversity and ecosystem services for the Americas. Edited by J. Rice, C.S. Seixas, M.E. Zaccagnini, M. Bedoya-Gaitán, and N. Valderrama. Secretariat of the Intergovernmental Science-Policy Platform on Biodiversity and Ecosystem Services, Bonn, Germany. 656 pp. (Available at https://www.ipbes.net/system/tdf/2018_americas_full_report_book_v5_pages_0.pdf?file=1\&type=node\&id=2 9404)

IPCC. 2014. Climate Change 2014: Synthesis Report. Contribution of Working Groups I, II, and III to the Fifth Assessment Report of the Intergovernmental Panel on Climate Change. Edited by R.K. Pachauri and L. Meyer. IPCC, Geneva, Switzerland, 151 pp. (Available from 
https://www.ipcc.ch/site/assets/uploads/2018/02/SYR_AR5_FINAL_full.pdf)

IPCC. 2018. Summary for policymakers. In Global warming of $1.5^{\circ} \mathrm{C}$. An IPCC special report on the impacts of global warming of $1.5^{\circ} \mathrm{C}$ above pre-industrial levels and related global greenhouse gas emission pathways, in the context of strengthening the global response to the threat of climate change. Edited by V. MassonDelmotte, P. Zhai, H.-O. Pörtner, D. Roberts, J. Skea, P.R. Shukla, A. Pirani, W. Moufouma-Okia, C. Péan, R. Pidcock, S. Connors, J.B.R. Matthews, Y. Chen, X. Zhou, M.I. Gomis, E. Lonnoy, T. Maycock, M. Tignor, and T. Waterfield. World Meteorological Organization, Geneva, Switzerland. 32 pp. (Available from http://www.ipcc.ch/report/sr15/)

Kilduff, D.P., L.W. Botsford, and S.L.H. Teo. 2014. Spatial and temporal covariability in early ocean survival of Chinook salmon (Oncorhynchus tshawytscha) along the west coast of North America. ICES J. Mar. Sci. 71(7): 1671-1682. doi:10.1093/icesjms/fsu031.

Leising, J., and S.J. Bograd. 2021. The California Current marine heatwave tracker-an experiemental tool for tracking marine heatwaves: California Current Project. Southwest Fisheries Science Centre. NOAA. (Available at https://www.integratedecosystemassessment.noaa.gov/regions/california-current/cc-projectsblobtracker)

Macdonald, J.S., J.C. Scrivener, D.A Patterson, and A. Dixon-Warren. 1998. Temperatures in aquatic habitats: the impacts of forest harvesting and the biological consequences to sockeye salmon incubation habitats in the interior of B.C. In Forest-fish conference: land mananagment practices affecting aquatic ecosystems. Proc. Forest-Fish Conf., May 1-4, 1996, Calgary. Edited by M.K. Brewin and D.M.A. Monita. Natural Resources Canada, Edmonton. pp. 313-324.

Mackas, D.L., S. Batten, and M. Trudel. 2007. Effects on zooplankton of a warmer ocean: recent evidence from the Northeast Pacific. Prog. Oceanogr. 75(2): 223-252. doi:10.1016/j.pocean.2007.08.010

NOAA. 2020. Global climate report-annual 2019. (Available at https://www.ncdc.noaa.gov/sotc/global/201913)

Ohlberger, J. 2013. Climate warming and ectotherm body size - from individual physiology to community ecology. Funct. Ecol. 27(4): 991-1001. doi:10.1111/1365-2435.12098

Ohlberger, J., E.J. Ward, D.E. Schindler, and B. Lewis. 2018. Demographic changes in Chinook salmon across the Northeast Pacific Ocean. Fish Fish. 19(3): 533-546. doi:10.1111/faf.12272

PCIC. 2019. Seasonal anomaly maps. (Available at https://www.pacificclimate.org/analysis-tools/seasonalanomaly-maps)

Ross, T. 2017. La Niña, the blob and another warmest year. In State of the physical, biological and selected fishery resources of Pacific Canadian marine ecosystems in 2016. Edited by P.C. Chandler, S.A. King, and J.L. Boldt. pp. 30-34. (Available at https://dfo-mpo.gc.ca/oceans/publications/soto-rceo/2016/index-eng.html)

Ross, T., and M. Robert. 2018. La Niña and another warm year. In State of the physical, biological and selected fishery resources of Pacific Canadian marine ecosystems in 2017. Can. Tech. Rep. Fish. Aquat. Sci. No. 3225. Edited by P.C. Chandler, S.A. King, and J.L. Boldt. pp. 27-32. (Available at https://dfompo.gc.ca/oceans/publications/soto-rceo/2017/index-eng.html)

Ross, T., and M. Robert. 2019. Another warm, but almost normal, year in the Northeast Pacific Ocean. In State of the physical, biological and selected fishery resources of Pacific Canadian marine ecosystems in 2018. Can. Tech. Rep. Fish. Aquat. Sci. No. 3314. Edited by J.L. Boldt, J. Leonard, and P.C. Chandler. Can. Tech. Rep. Fish. Aquat. Sci. No. 3314. pp. 15-20. (Available at https://dfo-mpo.gc.ca/oceans/publications/sotorceo/2018/index-eng.html)

Ross, T., and M. Robert. 2020. Are marine heatwaves the new normal for the Northeast Pacific Ocean? In State of the physical , biological and selected fishery resources of Pacific Canadian marine ecosystems in 2019. Can. Tech. Rep. Fish. Aquat. Sci. No. 3377. Edited by J.L. Boldt, A. Javorski, and P.C. Chandler. pp. 21-25. (Available at https://waves-vagues.dfo-mpo.gc.ca/Library/40884569.pdf)

Schindler, D.E., D.E. Rogers, M.D. Scheuerell, and C.A. Abrey. 2005. Effect of changing climate on zooplakton and juvenile sockeye salmon growth in Southwestern Alaska. Ecology 86(1): 198-209. doi:10.1890/03-0408]

Sharma, R., L.A. Velez-Espino, A.C. Wertheimer, N. Mantua, and R.C. Francis. 2013. Relating spatial and temporal scales of climate and ocean variability to survival of Pacific Northwest Chinook salmon (Oncorhynchus tshawytscha). Fish. Ocean. 22(1): 14-31. doi:10.1111/fog.12001.

Sopinka, N.M., C.T. Middleton, D.A. Patterson, and S.G. Hinch. 2016. Does maternal captivity of wild, migratory sockeye salmon influence offspring performance? Hydrobiologia 779(1): 1-10. doi:10.1007/s10750-0162763-1.

Tierney, K.B., D.A. Patterson, and C.J. Kennedy. 2009. The influence of maternal condition on offspring performance in sockeye salmon Oncorhynchus nerka. J. Fish Biol. 75(6): 1244-1257. doi:10.1111/j.10958649.2009.02360.x. 
White, T., J. Wolf, F. Anslow, and A. Werner. 2016. Indicators of climate change for British Columbia: update 2016. Victoria, B.C. doi:ISBN 0-7726-4732-1.

Whitney, C.K., S.G. Hinch, and D.A. Patterson. 2014. Population origin and water temperature affect development timing in embryonic sockeye salmon. Trans. Am. Fish. Soc. 143(5): 1316-1329. doi:10.1080/00028487.2014.935481.

Xu, Y., A.S. Decker, C.K. Parken, L.M. Ritchie, D.A. Patterson, and C. Fu. 2020. Climate effects on size-at-age and growth rate of Chinook Salmon (Oncorhynchus tshawytscha) in the Fraser River, Canada. Fish. Oceanogr. 29(5): 381-395. doi:10.1111/fog.12484.

Young, K., M. Galbraith, and I. Perry. 2018. Zooplankton status and trends in the central Strait of Georgia, 2017. In State of the physical, biological and selected fishery resources of Pacific Canadian marine ecosystems in 2017. Can. Tech. Rep. Fish. Aquat. Sci. No. 3225. Edited by P.C. Chandler, S. King, and J. Boldt. pp. 180 184. (Available at https://dfo-mpo.gc.ca/oceans/publications/soto-rceo/2017/index-eng.html) 